\title{
Rotavirus Antigen Measurement
}

National Cancer Institute

\section{Source}

National Cancer Institute. Rotavirus Antigen Measurement. NCI Thesaurus. Code C154827.

The determination of the rotavirus antigen present in a sample. 